\title{
Shopping, Surfing, and Sightseeing: Lessons from the City of Choice, Branson, Missouri
}

\author{
SUSAN SANDERS \\ University of Arkansas \\ USA
}

\section{INTRODUCTION}

Branson, the largest in the cluster of small towns in the southwestern section of Missouri has become the fastest growing, particularly in terms of greatest tax revenue, in the state as well as the Number One Coach Destination for American vacationers and the Number Two Vacation Destination in America, just behind Disney World in Orlando and just ahead of the Mall of America in Minneapolis.

4500 miles from Lisbon, nestled in the foothills of the Ozark Mountains, the once sleepy little town of Branson, with an actual population 3706 , is now the "country music capital of the universe," as so stated in 1991 by Morley Safer on the Number One news show "60 Minutes." This presentation will examine Branson, Missouri as an emblematic "City of Choice" in which the future public realm in America is designed by and constructed with an architecture of entertaining leisurely delights and an urban space confined to the interior of the automobile which seem to embody and epitomize our post-industrial desires as we search for "souvenirs of experience." If, the apparent "success" of Disney World, Mall of America and Las Vegas portend of a society that regards shopping as a cultural engagement, leisure as a means of self-definition and history as a passive theme-park experience, then one can propose that Americans love to shop, surf and sightsee. It will be the assumption of this paper that Americans love to shop, to shop in the traditional sense; to surf as it applies and extends shopping, thereby making it the most pervasive paradigm for the exercise of choice; and to sightsee as it is a spectator activity similar to TV watching and auto-driving in America.

The phenomena of Branson, Missouri is not specifically as just another historical theme-park adaptation with a country music flavor but more of an urban or Main Street mutation in the d-evolution of the American city-scape which normally falls into either a theme-park category, a leisure playground or a shopping experience. Superficially Branson does follow the typical development of the 'festival shopping/historical recreations' such as Boston's Quincy Market, Baltimore's Harbor Place, and Atlanta's Underground, essentially the American "consume-nation" of his-

tory into a voyeuristic shopping experience, yet it differs significantly in two realms. First, in its treatment or absence of a public realm or urban space and secondly, in its regard to the visitor's actual bodily or physical participation. Traditionally, festival development has relied on the 'Big Picture', or an overall thematic image presentation to the visitor, a true replica, an absolute fake, as Umberto Eco calls it, in fact a modern day better version of history.

However Branson does none of this. The primary focus on West Highway 76, the 'strip' of Branson, is on the distinct architectural images of each theater, stylistically and metaphorically linked to the individual entertainer. And secondly, the Branson Tourist is primarily a passive participant quite different from Las Vegas, the other major entertainment 'strip' in America, Branson offers a 'risk-free' vacation; there is no gambling or vice; no way to lose one's money, only ways to willingly spend it and all one has to do is watch.

Branson primarily exists today as the site/sight of consumption of live country music performances and merchandise at factory discount prices (malls are accessed from Highway 76) both potential indications of our contemporary conception of leisure. According to the OED, leisure is defined as "free time, time at one's disposal, enjoyment of this;" at leisure is defined as "not occupied, in unhurried manner." The Branson tourist is at leisure, to be sure but in a rather passive or voyeuristic state, only marginally moving from the front seat of the car to the seat in the theater to the booth in the restaurant to the store of the Mall to the bed of the motel, all indicating that watching or buying is the most active level of participation for the visitor. Certainly, in the Aristotelian sense of leisure, concisely defined as "an occasion for contemplation and reflection, a chance to look inward rather than outward," something has been dis- or misplaced as 5.8 million visitors flocked to Branson in 1994 for their family *vacations. The word 'vacation' and the word 'vacate' are derived from same Latin root word, vaco, which means to be empty.

Although part of the vacation experience and unoccupied only three months of the year are Branson's 21,500 outdoor seats specifically associated with the reenactment of historical scenarios indigenous to the area but more importantly, 
Branson, country music's Xanadu, promotes choice and choice of entertainment, as its primary and most marketable commodity, a virtual intangible as the essence of the town's economy, fitness and delight. One can 'shop' for the show to see, 'surf' the strip for one of the 36 theaters and 'sight-see' the stars of the shows, all at one's leisure. Sebastian de Grazia, author Of Work Time and Leisure states "The greater abundance of blessings that fall to men, the greater will be their need for wisdom, and wisdom is the virtue that cannot appear except in leisure."

\section{GEOGRAPHY}

The geography of Branson is defined by two distinct boundaries which establish the composition of the town. The "historic district" or original town center is defined by Lake Taneycomo establishing the southern and eastern boundaries containing the heart of the original community. More than 100 years old , the downtown area "thrives" today due to a "progressive city government and an energetic downtown business community", providing all the typical retail: the fudge factory, an original $5 \& 10$ and the souvenir T-shirt shops one has come to expect from any small town USA whose leading industry is tourism. The remaining geographic area of Branson and the area of interest is the 5-mile long stretch of West Highway 76. This three-lane road is an unplanned collision of the aesthetic sensibilities of the new found wealth of country music, of Wal-Mart, go-carts, puttputt golf, family style restaurants, souvenir shops, chateau motels, tee-shirt warehouses, and vulgar ostentatious facades clipped on to pre-fab metal buildings, all combining to create a "city" of unlimited choice. Similar in structure to the choice offered by cable TV, lots of channels to surf, lots of shows to choose, essentially, the contemporary illusion created as a substitute for democracy.

\section{DEMOGRAPHICS}

- 5,846,623 visitors in 1994,3706 actual residents 1994 , 25,000 workers in the service industry

- 4,884,500 visitors spending at least one night

- 3.5 average people stay an average of 2.5 days spending an average of $\$ 184.00$ per person

- 36 theaters, 34 churches, 50,000 indoor theater seats and 17,000 parking spaces required for the theaters

- 4000 seats in the Grand Palace, requiring 1333 parking spaces plus employee parking

- 21,500 outdoor theater seats and 7,000 campground sites

- 20,000 motel rooms requiring 20,000 parking spaces, 1 per room

- 25,000 simultaneous seating in restaurants

- 17 architects listed in the phone book

In an attempt to discover the "average" visitor to Branson and check my own preconceptions since there were no printed statistics, I contacted and spoke with both the Chamber of Commerce and the Ozark Marketing Council. The visitor profile, according to Jan Pinkerton, Executive Director of the
Ozark Marketing Council, is a family with school-age children and their vacation pattern follows the school year calendar. From September to May, during the 'shoulder seasons', early spring and late fall, families are most present on the weekends while 'empty nesters' or seniors occupy the attractions on the weekdays. Summer, when school is in recess, Branson goes into High Season and other than Christmas, is busy all week with an added increase of traffic, a major problem. During peak season up to 32,000 vehicles drive Highway 76 per day!

\section{SOUVENIRS}

With that many cars perhaps it is not a coincidence that one of the only two souvenirs I could find during my many sojourns to Branson would be a miniature mock Missouri plastic license plate with large type spelling out 'Highway 76'. There are no miniature theaters, no silver dollars, no mouse ears, virtually nothing that I could find that would signify or serve as the true artifact of the experience of Branson. I would propose that there is no "souvenir" to collect because of the intangible nature of the Branson experience. It is only the overwhelming number of choices, the vast quantity that imprints itself on the memory of the visitor to Branson, the sheer number of stars to see. The other one that I did find seemed to be a possible exception, however acting more like a surrogate than souvenir. It was a video tape of the Shoji Tabuchi Show for \$29.95, a memento of the show, an actual production of technology that provides a complete 'memory' of the experience rather than an evocative object the tape is the complete transcript of the show, potentially more surrogate than souvenir. Alan Millstein, editor of the Fashion Network Report writes "Entertainment retail is the most significant breakthrough of the ' 90 's. They(the stores) are the fair-haired children of the decade, because they make you feel good when you reach for your credit card. They don't sell necessities but shopping fantasy, and people are willing to pay handsomely for that."

\section{MUTATION OF TYPES}

Over the last quarter of the 20th century it is has become no surprise that America has been witnessing the proliferation of 'theme park cities' as our real urban centers began to deteriorate and become dark, dirty and dangerous places. Unfortunately, the so-called 'solution' to the abandonment of the urban environment consisted of a synthetic or cosmetic application of renovation and replication of a Disney-esque historicism of Main Street, USA plus the essential shoppingmall opportunity, in other words the establishment of what James Kunstler, author of The Geography of Nowhere, has called, "a cartoon culture" an extravagant unreality. In an attempt to examine the architectural or urban implications of the 'structure' or 'architecture' of Branson there existed a great difficulty in classifying it into any existing urban typology. However, to my mind it is the re-creation of "Main Street USA" that is the common denominator of these 
attempts at urban revitalization's or restorations, and it is on this basis that Branson may be understood and a categorization of four distinct types may be accomplished.

The first would be Disney World with its almost life-size idealized/utopic re-creation of Main Street as a sort of cartooned historical buffet town; second, would be the Mall of America, in Minneapolis, which has establishes and promotes Main Street as the extravagant shopping and consumptive experience; the Information Superhighway or Internet, the techno-tourist version of Main Street is the third and the Las Vegas Strip, is the fourth, the adult entertainment plus vice category. with the potential for wealth and fulfillment of forbidden desire. Branson, however, does not easily align with any of these four options. It lacks the complete, seamless "Big Picture" "world-within-aworld quality of Disney World and the Mall of America; the promise of a high-tech salvation on the Information Superhighway (map not included) and the authentic aura of glitz and glamour of Las Vegas. In short, Branson attempts to borrow from all four categories but in doing so only creates a mutation which contains various components of each type yet only fully expresses the semi-concealed latent desire to consume that is common to all.

Shopping, the process of exchange, acquisition and completion also informs Branson's architecture, in that it is an acquisition, the purchase of a representative style or aesthetic. The theater facades are ghastly metaphorical renditions and relations to the musical hits or personalities of the entertainers, from the "Blue Velvet" facade of Bobby Vinton's to the dryvit rock waterfall at Andy William's Moon River theater plus the only 'duck' of Branson, Kenny Rogers' riverboat, the Branson Belle, with all gambling associations vanquished. These "decorated sheds" to borrow Venturi's term, are very streetsmart particularly in their orientation to Highway 76 sacrificing any and all architectural considerations for the view from the road or the tourist's car even though most are also viewed in a distant perspective accidentally exposing the completely unadorned side elevations.

A prime example of the cosmetic approach to architecture and the street is the Grand Palace Theater. In an ongoing effort to disguise the five-story fly of the 4000- seat theater behind the "plantation-esque" facade, the owners over the years have painted and repainted this enormous box a variety of colors in optimistic hopes of having it blend with the sky. Basically the theaters all appear to function only as billboards for the entertainment and it is inconsequential this architecture, the exterior treatment except for its signage or graphic function, since all of the focus in on the interior of the theaters where the 'fun' is. Lobbies and restrooms command the visitor's attention prior to entry into the show with an extravagance that is has become a major marketing device. For example, the Shoji Tabuchi theater is unsurpassed in the over-the-top extravagance of the restrooms, complete with fireplaces, live orchids and African violets, and a billiard table for relaxation in the "gentlemen's" restroom. Recently, the lobby of the Grand Palace hosted a retro 50's exhibit that was incredibly complete in it's breadth and depth of authentic artifacts of furniture, clothing, automobiles, accessories and other 50's memorabilia.

In addition, to cosmetics or appearance, a valued component of the culture, Americans have also enthusiastically anticipated and embraced since the early 20 th century, the fulfillment of the prophecy that 'technology' or technological advancements will indeed free them from the necessity of work and that life will be composed of only leisure. As Jeremy Rifkin has written in his 1994 book, The End of Work", For more than a century utopian dreamers and men and women of science and letters have looked to a nearworkerless society of abundance and leisure."

Along with the reduction of the hours spent on the job, Americans now spend more and more meaningful hours at leisure pursuing their leisure activities. No longer limited to or required to use work as the primary self-defining vehicle, citizens now pursue leisure as a viable component of or for self-expression. Branson, a mutant city, hermetically sealed from the realities and requirements of a real city, is only to be consumed and purchased by the audience, appropriately and consequently fulfilling some of these desires. It is a very "family style" version of reality, quite similar to the architecture of our living rooms plus offering the opportunity for shopping, in a safe, clean and non-urban environment. Currently there are 36 theaters randomly sited along both sides of Highway 76, fast-food, go-carts and gift shops, barbecue restaurants and believe-it-or-not museums and motels disguised as riverboats with lots and lots of parking spaces to accommodate the 5.8 million visitors. It is a riskfree passive "reality" promoted by an economy of choice, a contemporary construct of America, suggesting a life composed of shopping, surfing and sightseeing.

Generally tourist attractions are an unplanned typology that provides direct access to the modern consciousness or 'world view' and in this, Branson excels if your world view or modern consciousness happens to be white, middle American, Christian in the post-Reagan America. Branson is the ultimate in "Couch Potato" vacation dreams; one can be entertained with the vast choices of shows just like channel surfing the TV at home, shopping is readily available and at a bargain price plus there are outdoor activities to amuse the children, all at an affordable price. Here is a description of Branson from The Economist, ".... town where everything is wholesome and clean and clear. There is no crack, no crime, no inner city blight. Almost everyone is white, speaks English, and shares the same values of God, Family and Country. Almost everyone who wants a job has one, and wealth is piling up on every side almost as high as the mountains. The schools are good, the country is pretty, there are plenty of shops and shows. The past is revered, as it should be, and the future is looked forward to. "

In 1991 Morley Safer of "60 Minutes" called Branson, the "country music capital of the Universe" and in that televised statement gave the impression that the success of Branson had indeed happened overnight. However, it actually began 
in 1901 with the publication of Harold Bell's novel The Shepherd of the Hills about life in the Ozarks and with the release of the film version of the novel in 1941 starring John Wayne, tourism continued its steady increase. The onset of the country music entertainment industry began in 1960 when the five Mabe brothers began performing a country music show known as the Baldknobbers on the Taneycomo lakefront in Branson and as the Visitor's Guide says "tourism began in earnest". By 1986 the growth of the music business has established Highway 76 as the most prominent location for the theaters.

\section{COUNTRY MUSIC HISTORY}

- 1987 ABC's Good Morning America uplinks from Silver Dollar City, the Baldknobbers perform for a nationwide audience

- 1987 Box Car Willie famed "hobo" performer becomes the first entertainer to buy a theater and perform on a regular basis in Branson

- 1989 Shoji Tabuchi opens a music show in the newly renovated theater formerly the Ozark Auto Show on Highway 76

- 1991 construction begins on the 4000-seat Grand Palace, hosts were to be Glenn Campbell and Barbara Mandrell

- 1993 Doc Severinsen, Bill Cosby, Julio Iglesias, Dwight Yoakam perform at the Grand Palace

- 1994 Ozarks Discovery IMAX Theater opens with a sixstory screen and 550 seats

- 1994 Bob Eubanks unveils the $\$ 25,000$ Game Show Spectacular

\section{CONCLUSION}

All this, and this is a very abbreviated chronology, to indicate the phenomenal growth of the country music industry which has become the mainstream music of America. Branson has developed almost entirely as a city of tourism or entertainment, the opportunity to enjoy oneself either through watching reenactments of "history" at Shepherd of the Hills Outdoor Theater or Silver Dollar City, or enjoying the zany antics and lively music of John Davidson, Roy Clark and Shoji Tabuchi. There are enough choices of shows to keep the tourist 'surfing' through the shows, for at least a month. It is the victory of the visual over the artificial, the tourist to Branson is there to surf or shop, essentially to watch or consume. Motels disguised as riverboats, theaters as plantations and museums of "believe-it-or-not" artifacts combine to make a "consume-nation of leisure", Branson is an artificial reality of replicants, (to borrow a term from "Blade Runner"), a place made of only an elaborate skin stretched over an architecture of leisure, a place devoid of place, there is no public space there is only the private interior of the automobile, the over-scaled lobbies of the theaters or the airconditioned stores of the malls, all defined and surrounded by the vast expanse of the parking lot.

\section{BIBLIOGRAPHY}

de Grazia, Sebastian. Of Time, Work and Leisure. First Vintage Books Edition, New York, 1994.

Kunstler, James Howard. The Geography of Nowhere. Simon\& Schuster, New York, 1993.

MacCannell, Dean. The Tourist. Schocken Books, New York, 1976.

Rifkin, Jeremy. The End of Work. G.P.Putnam's Sons, New York, 1995.

Rybczynski, Witold. Waitng for the Weekend. Viking Penguin, New York, 1991.

Stewart, Susan. On Longing: Narratives of the Miniature, the Gigantic, the Souvenir, the Collection. Johns Hopkins University Press, Baltimore, 1984. 